SHS Web of Conferences 24, 02012 (2016)

DOI: $10.1051 /$ shsconf/20162402012

(C) Owned by the authors, published by EDP Sciences, 2016

\title{
Experimental research on application of mutual-aid teaching method in technique teaching of university's football elective course
}

\author{
Jiarong $\mathrm{Wu}$ \\ Zhuhai College of Jilin University, Zhuhai, Guangdong, China
}

\begin{abstract}
With the social development and reform of education system, the quality-oriented education and lifelong education gradually become education reform goals of colleges and universities, the physical education of the higher education and university are also developed. This research adopts the literature data method, questionnaire method, experimental method, mathematical statistics or other methods to do experiments for the students who take the football elective course (a total of 36 class hours per semester) in Zhuhai College of Jilin University with the mutual-aid teaching method. The experimental results show that: First, there is a significant difference between achievements of the specific football technique of the students in the experimental group and the students in the control group $(\mathrm{P}<0.05)$; second, in the teaching evaluation, the failure rate of the students in the experimental group significantly reduces, and the pass rate and good rate significantly increases after experiment; third, the majority of students accept the mutual-aid teaching method; fourth, the mutual-aid teaching method can be used to significantly improve the learning motivation level of the students.
\end{abstract}

Keywords: mutual-aid teaching method; university; football elective course; technology; teaching design; experimental research

\section{INTRODUCTION}

In the $17^{\text {th }}$ century, Comenius - an educator in Czech Republic of Europe created an organizational teaching mode that is similar to the teaching \& teaching system in the course of long-term educational practice. Therefore, the classroom teaching is always inherited as a main organizational form of school teaching. Until the early $20^{\text {th }}$ century, the teacher-directed and inspired teaching strategies and students' passive learning have become a sole and invariable mode. The modern multimedia teaching conditions can not only improve the expanding space of the teachers, but also save teachers resources. The classroom teaching gives full play to the leading role of teachers; if teaching is given to the class as a unit, it will be convenient and conducive to management. Based on the consistency with the developing teaching theory and practice, and direction of the education, science and technology, innovation and other requirements, especially at the request of the concept of "quality-oriented education" in China, more and more educators find shortcomings in the class-based teaching; the independence of the subject in the traditional teaching system of classroom is subject to certain restrictions, and the classroom discipline and performance appraisal system of the students are also limited, and the creativity is restrained without complete development; the programmatic classroom teaching content and methods make many teachers only abide by the teaching content and teaching process; the classroom teaching is unable to fully mobilize the enthusiasm and creativity of the teachers and students, and its teaching content and methods are too mechanized, and the teaching content and teaching objectives only have a uniform requirement on the students; obviously, the classbased teaching is not implemented according to the student's personality and differences, which is not conducive to the principle of personality. Higher education and university's physical education are developed, so the traditional teaching method is unable to keep up with the needs of modern development; therefore, the mutual-aid teaching model plays a significant role in the university's physical education.

Nowadays, the campus football has become a hot spot of school sports. On February 27, 2015, an Overall Program of Chinese Football Reform and Development was approved in the tenth session of the Cen- 
Table 1. Statistical table of validity test of the questionnaire $(\mathrm{N}=35)$

\begin{tabular}{llllll}
\hline Degree & Very effective & Effective & General & Not quite effective & Invalid \\
\hline Expert opinion & 14 & 15 & 6 & & \\
Percentage (\%) & 40 & 42.86 & 17.14 & & \\
\hline
\end{tabular}

tral Leading Group of Comprehensively Deepening Reform, which proposed "reform and promote the development of campus football"; therefore, the football teaching has become a hot spot and difficulty, so there is a need to do more work to improve the teaching methods and enhance the quality of teaching. How to rapidly impart on football skills and guide students to learn and accept the knowledge and skills well is an important task for each football educators confronted in a long term. The mutual-aid teaching method has achieved a very good result in many other physical educations. The research on the application of the mutual-aid teaching method in the football teaching has an important role and significance on innovating the football teaching methods and means, solving "hungry and hard-to-digest" problems of the students in the football course, and promoting and popularizing the teaching of the football elective course.

\section{RESEARCH OBJECTS AND RESEARCH METHODS}

\subsection{Research objects}

The research objects are 140 male students from the football elective class in Level 2012 and 2013 of Zhuhai College of Jilin University, of which 70 students are randomly selected as the experimental group, and the remaining 70 students as the control group.

\subsection{Research methods}

\subsubsection{Literature data method}

According to the requirement of the research in this paper, we can have a more comprehensive understanding of the research status and current issue in the field of this topic through retrieving and referring to the National Press Index, China Journal Net and other related sites, and consulting the relevant physical education, sports theory, sports statistics, sports test and evaluation, and other related books and a large number of literature data, thus providing a theoretical and methodological basis for this research.

\subsubsection{Experimental test method}

Before experiment, there is a need to respectively test the basic physical index (age, height and weight), physical quality index $(30 \mathrm{~m}$ sprint, $25 \mathrm{~m}$ shuttle run, standing long jump, chin-ups) and index of specific football technique (juggling, fixed passing, dribbling and shooting) for two groups of students. After exam- ination, the test result is $\mathrm{P}>0.05$, indicating that there is no significant difference between two groups of students, and it is in line with the requirements of the experimental design.

\subsubsection{Questionnaire method}

The validity and reliability test has been done for the questionnaire.

(1) The relevant experts are invited again to do the validity test for the content of the revised questionnaire (see Table 1). The test results show that the design of the questionnaire has validity.

(2) Reliability test of the questionnaire

The "test-retest reliability" evaluation method is used, and a second round of questionnaires is issued to seven experts after three weeks. Compare the recovered questionnaires and previous questionnaires after calculating the correlation coefficients of the questionnaire. $\mathrm{r}=0.832$ and $\mathrm{P}<0.01$, which are in line with the statistical requirements, indicating that the questionnaire has a high reliability.

(3) 140 copies of questionnaires are issued to the students who attend the football elective course, and 140 copies are recovered from them, with a recovery rate of $100 \%$, so as to acquire the students' awareness of the application effect of the mutual-aid teaching method in teaching university's football elective course.

\section{Mathematical statistics}

The social science statistical software (SPSS15.0) is used to implement $\mathrm{T}$ test for various indexes of the experimental class and control class, compare the significance of differences and analyze the experimental results, thereby obtaining the experimental scientific basis.

\section{RESULT AND ANALYSIS}

\subsection{Difference test for the basic situation of all stu-} dents before teaching

$\mathrm{T}$ test is given to the basic situation (age, height and weight) of the students who attend the football elective course. And then comparative analysis is given by $\mathrm{T}$ test of independent samples. The results are shown in Table 2.

Compared with the basic situation of the students in the experimental group and the students in the control group, there is no significant difference between two groups in terms of the average age, height and weight $(\mathrm{P}>0.05)$. 
SSHE 2015

Table 2. Difference test table of the student's physical index

\begin{tabular}{|c|c|c|c|c|c|}
\hline \multirow[b]{2}{*}{ Item } & \multicolumn{2}{|c|}{ Experimental group } & \multicolumn{2}{|c|}{ Control group } & \multirow[b]{2}{*}{$\mathrm{P}$} \\
\hline & $\bar{x}$ & $\mathrm{~S}$ & $\bar{x}$ & $\mathrm{~S}$ & \\
\hline Height (cm) & 173.28 & 3.82 & 172.97 & 4.29 & $>0.05$ \\
\hline Weight (kg) & 67.00 & 3.95 & 65.96 & 3.13 & $>0.05$ \\
\hline Age (y) & 20.35 & 0.82 & 20.44 & 0.87 & $>0.05$ \\
\hline
\end{tabular}

Table 3. Performance difference test table of the student's specific technique level before teaching

\begin{tabular}{llll}
\hline \multirow{2}{*}{ Item } & Experimental group & Control group & \\
\cline { 2 - 4 } & $\bar{\chi} \pm s$ & $\bar{\chi} \pm s$ & $\mathrm{P}$ \\
Juggling & $43.59 \pm 1.24$ & $43.62 \pm 1.32$ & $>0.05$ \\
Fixed passing & $41.56 \pm 1.71$ & $41.57 \pm 1.59$ & $>0.05$ \\
20m dribbling and shooting & $44.26 \pm 1.33$ & $44.24 \pm 1.76$ & $>0.05$ \\
\hline
\end{tabular}

Table 4. Statistical table of changes of physical quality of students in the experimental group

\begin{tabular}{llll}
\hline Item & Before experiment & After experiment & P \\
\hline 30m sprint & $4.28 \pm 0.12$ & $3.89 \pm 0.17$ & $<0.05$ \\
25m shuttle run & $21.81 \pm 0.35$ & $19.56 \pm 0.49$ & $<0.05$ \\
Standing long jump & $1.96 \pm 0.02$ & $2.08 \pm 0.33$ & $>0.05$ \\
Chin-ups & $6.33 \pm 0.04$ & $7.86 \pm 0.56$ & $<0.05$ \\
\hline
\end{tabular}

\subsection{Difference test for the special technical level of all students before teaching}

Before experiment, two special teachers who have involved in many years of football teaching give a score to the technique of juggling, fixed passing, $20 \mathrm{~m}$ dribbling and shooting for 140 students. The score has four levels - excellent (85- 100 points), good (7584 points), pass ( $60-74$ points) and fail (60 points or less). As can be seen from Table 3, the number of students who are tested with the performance of football technique in the experimental group and the control group respectively accounts for $44.29 \%$ and $42.86 \%$, which is the most. The number of students who are tested with the performance distributed in different grades in the experimental group and the control group is basically the same. Meanwhile, after comparative analysis by $\mathrm{T}$ test, there is no significant difference between two groups in terms of the specific technique level $(\mathrm{P}>0.05)$.

Thus, through the difference test of the physical index, the interest and attitude index, the physical quality index and the specific technique index of the students in the experimental group and the students in the control group, there is no significant difference $(\mathrm{P}>$ 0.05 ), thus ensuring the fairness of the experimental teaching and comparative analysis.

\subsection{Analysis of changes in the physical quality of students in the experimental group and students in the control group}

After finishing experiment, the physical quality and technical assessment shall be made for the students in the experimental class and the students in the control class by teaching experiment, and then the questionnaires are issued to the students. The changing and developing data of the physical quality and technique of the students in the experimental class and the students in the control class can be obtained by the test and recovered questionnaires, and then collection, collation and comparative analysis are given to these data.

\subsubsection{Changes in physical quality of students in the experimental group}

After a semester of football teaching, the horizontal comparison of the physical quality of students in the experimental class shows that, there is no significant change in the performance of the standing long jump for the students in the experimental class; there is a significant change in the performance of $30 \mathrm{~m}$ sprint, $25 \mathrm{~m}$ shuttle run and chin-ups $(\mathrm{P}<0.05)$, with a great improvement in the performance. Thus, the mutual-aid teaching method plays a significant role in promoting the physical quality of students (see Table 4).

\subsubsection{Changes in physical quality of students in the control group}

As can be seen from the test results of the physical quality of students, the performance of $30 \mathrm{~m}$ sprint, standing long jump and chin-ups has a certain extent of improvement without significant changes before and after experiment $(\mathrm{P}>0.05)$; the performance of $25 \mathrm{~m}$ shuttle run has a significant change. Thus, the traditional teaching has a certain impact on the im- 
SHS Web of Conferences

Table 5. Statistical table of changes of physical quality of students in the control group

\begin{tabular}{llll}
\hline Item & Before experiment & After experiment & $\mathrm{P}$ \\
\hline 30m sprint & $4.31 \pm 0.09$ & $4.12 \pm 0.13$ & $>\mathrm{O} .05$ \\
25m shuttle run & $21.74 \pm 0.13$ & $19.65 \pm 0.31$ & $<\mathrm{O} .05$ \\
Standing long jump & $1.97 \pm 0.07$ & $1.99 \pm 0.31$ & $>\mathrm{O} .05$ \\
Chin-ups & $6.45 \pm 0.09$ & $7.16 \pm 0.73$ & $>\mathrm{O} .05$ \\
\hline
\end{tabular}

Table 6. Changes in the performance of specific technique level of students in the experimental group

\begin{tabular}{llll}
\hline \multirow{2}{*}{ Item } & \multicolumn{2}{l}{ Before experiment } & After experiment \\
\cline { 2 - 3 } & $\bar{\chi} \pm s$ & $\bar{\chi} \pm s$ & $\mathrm{P}$ \\
Juggling & $43.59 \pm 1.24$ & $76.31 \pm 1.37$ & $<0.05$ \\
Fixed passing & $41.56 \pm 1.71$ & $74.86 \pm 1.48$ & $<0.05$ \\
20m dribbling and shooting & $44.26 \pm 1.33$ & $75.79 \pm 1.56$ & $<0.05$ \\
\hline
\end{tabular}

Table 7. Changes in the performance of specific technique level of students in the control group

\begin{tabular}{llll}
\hline & Before experiment & After experiment & \\
\cline { 2 - 3 } Item & $\bar{\chi} \pm s$ & $\bar{\chi} \pm s$ & \\
Juggling & $43.62 \pm 1.32$ & $66.31 \pm 1.37$ & $<0.05$ \\
Fixed passing & $41.57 \pm 1.59$ & $64.86 \pm 1.48$ & $<0.05$ \\
20m dribbling and shooting & $44.24 \pm 1.76$ & $55.79 \pm 1.56$ & $>0.05$ \\
\hline
\end{tabular}

Table 8. Comparison table of the performance of specific technique level of students in the experimental group and students in the control group

\begin{tabular}{llll}
\hline \multirow{2}{*}{ Item } & Before experiment & After experiment & \\
\cline { 2 - 4 } & $\bar{\chi} \pm s$ & $\bar{\chi} \pm s$ & \\
Juggling & $76.31 \pm 1.37$ & $66.31 \pm 1.37$ & $<0.05$ \\
Fixed passing & $74.86 \pm 1.48$ & $64.86 \pm 1.48$ & $<0.05$ \\
20m dribbling and shooting & $75.79 \pm 1.56$ & $55.79 \pm 1.56$ & $<0.05$ \\
\hline
\end{tabular}

provement of the physical quality of the students (see Table 5).

3.4 Analysis of changes in the specific football technique of students in the experimental group and students in the control group

\subsubsection{Changes in the specific football technique of students in the experimental group}

After a semester of teaching, two special teachers who have involved in many years of football teaching test the specific football technique of students in the experimental group. The result (see Table 3-5) shows that, there is a significant difference between the performances of juggling, fixed passing, $20 \mathrm{~m}$ dribbling and shooting before and after experiment $(\mathrm{P}<0.05)$. It indicates that the specific football technique of students in the experimental group has a relatively large improvement, and the mutual-aid teaching method plays a certain role in improving the specific football technique of students.

\subsubsection{Changes in the specific football technique of} students in the experimental group

After a semester of teaching, two special teachers who have involved in many years of football teaching test the specific football technique of students in the control group. The test result (see Table 7) shows that, there is a great change in the performance of juggling and fixed passing before and after experiment $(p<0.05)$; there is a little change in the performance of $20 \mathrm{~m}$ dribbling and shooting $(\mathrm{P}>0.05)$. It indicates that the traditional teaching also has a certain impact on improving the specific football technique.

\subsubsection{Comparative analysis of changes in specific football technique of students in the experi- mental group and in the control group}

Compared with the performance of the specific football technique of students in the experimental group and in the control group (see Table 8), there is a significant difference between the performance of juggling, fixed passing and $20 \mathrm{~m}$ dribbling and shooting in the experimental group and in the control group ( $p$ 
SSHE 2015

Table 9. Statistical table of the performance of specific technique of two groups of students after experiment

\begin{tabular}{|c|c|c|c|c|c|c|c|c|c|}
\hline \multirow{2}{*}{ Item } & \multirow{2}{*}{ Group } & \multicolumn{2}{|c|}{ Performance } & \multirow[b]{2}{*}{ Good } & \multirow[b]{2}{*}{$\%$} & \multirow[b]{2}{*}{ Pass } & \multirow[b]{2}{*}{$\%$} & \multirow[b]{2}{*}{ Failure } & \multirow[b]{2}{*}{$\%$} \\
\hline & & Excellent & $\%$ & & & & & & \\
\hline \multirow[t]{2}{*}{ Juggling } & Experimental group & 16 & 22.86 & 20 & 28.57 & 32 & 45.71 & 2 & 2.86 \\
\hline & Control group & 13 & 18.57 & 18 & 25.71 & 31 & 44.28 & 8 & 11.43 \\
\hline \multirow[t]{2}{*}{ Fixed passing } & Experimental group & 15 & 21.43 & 24 & 34.29 & 28 & 40 & 3 & 4.28 \\
\hline & Control group & 12 & 17.14 & 17 & 24.29 & 32 & 45.71 & 9 & 12.86 \\
\hline \multirow{2}{*}{$\begin{array}{l}20 \mathrm{~m} \text { dribbling and } \\
\text { shooting }\end{array}$} & Experimental group & 15 & 21.43 & 22 & 31.43 & 29 & 41.43 & 4 & 5.71 \\
\hline & Control group & 11 & 15.71 & 18 & 25.71 & 31 & 44.29 & 10 & 14.29 \\
\hline
\end{tabular}

Table 10. Survey and statistics of the satisfaction degree on classroom teaching for students in the experimental group

\begin{tabular}{|c|c|c|c|c|c|c|c|c|c|}
\hline & \multirow{2}{*}{$\frac{\text { Number of people }}{\mathrm{n}}$} & \multicolumn{2}{|c|}{ Very satisfied } & \multicolumn{2}{|c|}{ More satisfied } & \multicolumn{2}{|c|}{ General } & \multicolumn{2}{|c|}{ Not satisfied } \\
\hline & & $\mathrm{n}$ & $\%$ & $\mathrm{n}$ & $\%$ & $\mathrm{n}$ & $\%$ & $\mathrm{n}$ & $\%$ \\
\hline Experimental group & 70 & 34 & 48.57 & 23 & 32.86 & 13 & 18.57 & 0 & 0 \\
\hline Control group & 70 & 18 & 25.71 & 27 & 38.57 & 14 & 20 & 11 & 15.71 \\
\hline
\end{tabular}

$<0.05)$. The performance of specific football technique of students in the control group has a certain extent of improvement, but the extent of improvement is far less than that of the students in the experimental group. Thus, the mutual-aid teaching method plays an important role in improving the specific football technique of students.

\subsection{Evaluation of football elective course of students in the experimental group and in the control group}

After evaluation of various football techniques of the students in the experimental group and the control group according to the football teaching evaluation method (see Table 9), each level of the students in the experimental group and the control group has varying degrees of improvement after experiment. In particular, the failure rate of the students in the experimental group reduces significantly, while the pass rate and good rate increase significantly. It indicates that the mutual-aid teaching method allows teachers to preferably select the appropriate teaching methods and organize teaching based on the actual situation of the students, so the students can have a greater improvement on the original basis. The students can achieve teaching objectives through their own efforts, and feel the joy of success and potentially generate a sense of accomplishment, thus stimulating the students' desire to learn, improving the students' interest in learning, and optimizing the teaching organization.

\subsection{Survey result analysis of mutual-aid teaching method after experiment}

After survey and analysis of the students' satisfaction degree on two kinds of teaching methods, the questionnaire findings (see Table 10) show that, in the experimental group, 34 students are very satisfied with the mutual-aid teaching method used in the football elective course, accounting for $48.57 \%$ of the total number in the experimental group; 23 students are more satisfied with it, accounting for $32.86 \%$ of the total number in the experimental group; 13 students consider that it is general, accounting for $18.57 \%$ of the total number in the experimental group. Thus, the mutual-aid teaching method is supported by the vast majority of students. In the control group, only 18 students are very satisfied with the traditional teaching method used in the football elective course, accounting for $25.71 \%$ of the total number; 27 students are more satisfied with it, accounting for $38.57 \%$ of the total number; 14 students consider that it is general, accounting $20 \%$ of the total number; 11 students are not satisfied with it, accounting for $15.71 \%$ of the total number. Thus, the vast majority of students are just relatively satisfied with the traditional teaching method used in the classroom, and even a small number of students are not satisfied with the traditional teaching method. It also has a certain impact on the teaching effect of the football elective course. Therefore, in terms of the teaching effect and the student's feeling, it fully indicates that, it is feasible to use the mutual-aid teaching method in the specific football teaching.

\subsection{Survey and analysis of the students' interest and} attitude towards two kinds of teaching methods

After statistics of the student's learning interest and attitude, the survey and analysis (see Table 11) shows that, $52.86 \%$ of the students in the experimental group and only $37.14 \%$ of the students in the control group consider that it is good to be fond of football and they can fully experience joy from football; $50 \%$ of the students in the experimental group and only $32.86 \%$ of the students in the control group consider that it is good to develop hobby and expertise in football; $48.57 \%$ 
SHS Web of Conferences

Table 11. Survey and statistics of the interest and attitude of students in the experimental group and control group

\begin{tabular}{|c|c|c|c|c|c|c|c|}
\hline \multirow{2}{*}{ Content } & \multirow{2}{*}{ Group } & \multicolumn{2}{|c|}{ Good } & \multicolumn{2}{|c|}{ General } & \multicolumn{2}{|c|}{$\mathrm{Bad}$} \\
\hline & & $\mathrm{n}$ & $\%$ & $\mathrm{n}$ & $\%$ & $\mathrm{n}$ & $\%$ \\
\hline \multirow[t]{2}{*}{$\begin{array}{l}\text { Be fond of football and fully experience joy from foot- } \\
\text { ball }\end{array}$} & $\begin{array}{l}\text { Experimental } \\
\text { group }\end{array}$ & 37 & 52.86 & 30 & 42.86 & 3 & 4.29 \\
\hline & Control group & 26 & 37.14 & 33 & 47.14 & 11 & 15.71 \\
\hline \multirow[t]{2}{*}{ Develop hobby and expertise in football } & $\begin{array}{l}\text { Experimental } \\
\text { group }\end{array}$ & 35 & 50 & 29 & 41.43 & 6 & 8.57 \\
\hline & Control group & 23 & 32.86 & 33 & 47.14 & 14 & 20 \\
\hline \multirow[t]{2}{*}{$\begin{array}{l}\text { Extent of understanding football and mastering the basic } \\
\text { technique }\end{array}$} & $\begin{array}{l}\text { Experimental } \\
\text { group }\end{array}$ & 34 & 48.57 & 32 & 45.71 & 4 & 5.71 \\
\hline & Control group & 21 & 30 & 36 & 51.43 & 13 & 18.57 \\
\hline
\end{tabular}

Table 12. Survey and statistics of the recognition on two kinds of teaching methods by the students in the experimental group

\begin{tabular}{|c|c|c|c|c|c|c|c|}
\hline \multirow{2}{*}{ Content } & \multirow{2}{*}{ Group } & \multicolumn{2}{|l|}{ Yes } & \multicolumn{2}{|c|}{ General } & \multicolumn{2}{|l|}{ No } \\
\hline & & $\mathrm{n}$ & $\%$ & $\mathrm{n}$ & $\%$ & $\mathrm{n}$ & $\%$ \\
\hline \multirow{2}{*}{$\begin{array}{l}\text { Be beneficial to more harmonious relationship } \\
\text { between teachers and students }\end{array}$} & Experimental group & 58 & 82.86 & 12 & 17.14 & 0 & 0 \\
\hline & Control group & 21 & 30.00 & 47 & 67.15 & 2 & 2.85 \\
\hline \multirow{2}{*}{$\begin{array}{l}\text { Cultivate the students' spirit of solidarity and } \\
\text { collaboration }\end{array}$} & Experimental group & 61 & 87.14 & 9 & 12.86 & 0 & 0 \\
\hline & Control group & 19 & 27.14 & 48 & 68.57 & 3 & 4.29 \\
\hline \multirow[t]{2}{*}{ Exert the subjective role of students } & Experimental group & 59 & 84.29 & 11 & 15.71 & 0 & 0 \\
\hline & Control group & 16 & 22.86 & 50 & 71.43 & 4 & 5.71 \\
\hline \multirow[t]{2}{*}{ Dig up the potential of students } & Experimental group & 47 & 67.14 & 23 & 32.86 & 0 & 0 \\
\hline & Control group & 15 & 21.43 & 44 & 62.86 & 11 & 15.71 \\
\hline \multirow{2}{*}{$\begin{array}{l}\text { Cultivate the students' competitive conscious- } \\
\text { ness }\end{array}$} & Experimental group & 60 & 85.71 & 10 & 14.29 & 0 & 0 \\
\hline & Control group & 18 & 25.72 & 46 & 65.71 & 6 & 8.57 \\
\hline \multirow[t]{2}{*}{$\begin{array}{l}\text { Embody the teaching principle of teaching } \\
\text { students in accordance with their aptitude }\end{array}$} & Experimental group & 49 & 70.00 & 21 & 30 & 0 & 0 \\
\hline & Control group & 17 & 24.29 & 46 & 65.71 & 7 & 10 \\
\hline
\end{tabular}

of the students in the experimental group and only $30 \%$ of the students in the control group consider that it is good to the extent of understanding football and mastering the basic technique. In general, through comparison with the experimental group and control group, the interest and attitude of the students in the experimental group are relatively good. Thus, the implementation of the mutual-aid teaching in the football elective course plays a significant role in improving the students' learning interest.

\subsection{Survey and analysis of the students' recognition on two kinds of teaching methods after teaching}

After statistics of the recognition on two kinds of teaching methods by the students in the experimental group, the survey and analysis (see Table 12) shows that, $82.86 \%$ of the total number in the experimental group believes that the mutual-aid teaching method is beneficial to more harmonious relationship between teachers and students, while $30.00 \%$ of the total number in the control group believes that the traditional teaching method is beneficial to more harmonious relationship between teachers and students; $87.14 \%$ of the total number in the experimental group believes that the mutual-aid teaching method can cultivate the students' spirit of solidarity and collaboration, while $27.14 \%$ of the total number in the control group believes that the traditional teaching method can cultivate the students' spirit of solidarity and collaboration; $84.29 \%$ of the total number in the experimental group believes that the mutual-aid teaching method can exert the subjective role of students, while $84.29 \%$ of the total number in the control group believes that the traditional teaching method can exert the subjective role of students; $67.14 \%$ of the total number in the experimental group believes that the mutual-aid teaching method can discover the potential of students, while $21.43 \%$ of the total number in the control group believes that the traditional teaching method can explore the potential of students; $85.71 \%$ of the total number in the experimental group believes that the mutual-aid teaching method can cultivate the students' competitive consciousness, while $25.72 \%$ of the total number in the control group believes that the traditional teaching method can cultivate the students' competitive consciousness; $70.00 \%$ of the total number in the experimental group believes that the mutual-aid teaching method can embody the teaching principle of teaching students in accordance with their 
aptitude, while $24.29 \%$ of the total number in the control group believes that the traditional teaching method can embody the teaching principle of teaching students in accordance with their aptitude. Thus, the degree of recognition of the mutual-aid teaching method is better than that of the traditional teaching method; the vast majority of students recognize that the mutual-aid teaching method can be used to cultivate the students' spirit of solidarity and collaboration, cultivate the students' competitive consciousness, exert the subjective role of students, be beneficial to more harmonious relationship between teachers and students, embody the teaching principle of teaching students in accordance with their aptitude and explore the potential of students.

\section{CONCLUSION AND SUGGESTION}

\subsection{Conclusion}

To apply the mutual-aid teaching method in the teaching process of university's football elective course, first, there is a need to research and understand the differences between the basic situation and specific technique of students, and make a rational grouping; second, the students in the experimental group and control group adopt uniform teaching programs, teaching schedule and teaching content, and implement uniform examination content.

The experimental result of the mutual-aid teaching method shows that, the specific football technique has a great improvement, which is conducive to helping students learn and master the football technique. After comparison, there is a significant difference between the performances of juggling, fixed passing, $20 \mathrm{~m}$ dribbling and shooting for the students in the experimental group and the students in the control group ( $\mathrm{P}$ $<0.05$ ). The performance of specific football technique of students in the control group has a certain extent of improvement, but the extent of improvement is far less than that of the students in the experimental group. Thus, the mutual-aid teaching method is better than the traditional teaching method and plays an important role in improving the specific football technique of students.

After evaluation of various football techniques of the students in the experimental group and the control group according to the football teaching evaluation method, each level of the students in the experimental group and the control group has varying degrees of improvement after experiment. In particular, the failure rate of the students in the experimental group reduces significantly, while the pass rate and good rate increase significantly.

After survey and analysis of the recognition on the mutual-aid teaching method, the vast majority of students realize that the mutual-aid teaching method can be used to cultivate the students' spirit of solidarity and collaboration, cultivate the students' competitive consciousness, exert the subjective role of students, be beneficial to more harmonious relationship between teachers and students, embody the teaching principle of teaching students in accordance with their aptitude and discover the potential of students.

The mutual-aid teaching method can be used to improve the learning motivation level of students. The survey result shows that, the students in the experimental group have a higher requirement on the satisfaction, interest and attitude towards the football course than that of the students in the control group, and the learning motivation level of the students in the experimental group is significantly higher than that of the students in the control group.

\subsection{Suggestion}

The use of the mutual-aid teaching method in the football elective course should comprehensively consider various aspects of influencing factors, and make a rational grouping for the students; in the entire teaching process, there is a need to fully reflect the thought of mutual-aid teaching, and truly realize individualized teaching, so every student can have varying degrees of improvement.

For the mutual-aid teaching method, it allows teachers to act or guide teaching in a "captive style" and "sheep-herding style". The teachers should observe, guide, adjust, correct error and exchange, adjust and combine the optimal mutual aid of the students with different football technique levels, provide mutual aid in the adjustment and make adjustment in mutual aid. They should also experience the learning effect in mutual-aid teaching and have a common improvement in the feedback.

In the process of teaching by the use of the mutual-aid teaching method, there is a need to gradually form different levels of mutual-aid groups step by step. In the implementation of classroom teaching by the use of the mutual-aid teaching method, there is a need to improve the common practice of classroom teaching, and perfect the classroom management; there is also a need to timely address and resolve the problems detected, and make a summary conscientiously, and further make improvement and summarization.

In teaching of the university's football elective course for boy students, this paper selects two boy's classes in Zhuhai College of Jilin University as experimental subjects to do teaching experiment by the use of the mutual-aid teaching method; the experiment has a good effect, and the physical quality and technical ability of the students has a great improvement, but it is not implemented in the tactical teaching, so it requires to be further researched. For other experimental subjects such as mixed-sex classes and girl's classes, there is no experimental research of the mutual-aid teaching; it is recommended to apply the mutual-aid teaching method to different types of universi- 


\section{SHS Web of Conferences}

ties and different natures of research objects for experimental tests.

The mutual-aid teaching method is used for teaching the football elective course. And there is a need to establish a scientific and rational evaluation system for different students, and do further research.

\section{REFERENCES}

[1] Zhong Qiquan compiled. 1998. Development of modern teaching theory. Beijing: Education Science Press, 130.151

[2] Mao Zhenming. 1996. Scientific exploration of physical education. Beijing: Higher Education Press, 6.

[3] Mao Zhenming. 2000. Research on physical education model. Journal of Guangzhou Sports University, (4): 23-25.
[4] Chen Xiaorong. 2001. Research principle and methods of sports science. Beijing: Beijing Sport University Press, 38-46.

[5] Zhao Li. 2000. Research on structure of physical education model group. Journal of Beijing Sport University, (4): 12-14.

[6] Lin Yong. 2001. "Four prohibitions" in hierarchical teaching method of physical education class. Chinese School Physical Education, (4): 5.

[7] Song Yuanping. 2001. Experiment research on the teaching method of "hierarchical adjustment in class". China Sports Science and Technology, (7): 16-17.

[8] Yan Zhiping. 2001. On the teaching model of cooperation innovation. Sports Science Research, (9): 28-30.

[9] Yan Zhiping. 2001. On the teaching model of cooperation innovation. Sports Science, (9), 28-30.

[10] Jin Yong. 2004. Discussion and analysis on teaching practices of "independence, cooperation and error correction" in physical education class. Journal of Nanjing Institute of Physical Education, 18 (3): 114-115. 